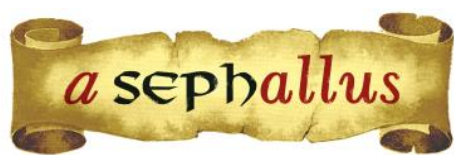

Revista aSEPHallus de Orientação Lacaniana

Núcleo Sephora de Pesquisa sobre o Moderno e o Contemporâneo

ISSN $1809-709 \mathrm{X}$

\title{
Par ou Ímpar? Uma leitura dos impasses das parcerias amorosas entre homens e mulheres na clínica contemporânea
}

\author{
Márcia Infante Vieira \\ Psicanalista \\ Psicóloga graduada pela Pontifícia Universidade Católica do Rio de Janeiro/PUC-RJ (Rio de Janeiro, Brasil) \\ Mestre em Teoria Psicanalítica pelo Programa de Pós-graduação da Universidade Federal do Rio de \\ Janeiro/UFRJ (Rio de Janeiro, Brasil) \\ E-mail: marciainfante@oi.com.br
}

\begin{abstract}
Resumo: Essa pesquisa estuda o desacordo existente entre o desejo e o discurso de homens e mulheres nos dias de hoje. Dentro de uma perspectiva psicanalítica, avaliamos as transformações que teriam ocorrido com as subjetividades responsáveis por as fazerem deslizar do laço do casamento, da modernidade, para um exílio em que muitos se encontram atualmente. Parece que a liberação sexual estendeu-se e, por vezes, adiou a escolha de um homem por uma mulher e vice-versa. Escolher implica em se castrar. No entanto, o sujeito contemporâneo, atravessado pela ideologia de que é proibido proibir, em conjunto com a lógica de um capitalismo consumista, acredita 'tudo poder'. Essa reflexão desemboca na prática psicanalítica visando a demanda desse sujeito contemporâneo e, exige uma nova escuta e uma nova prática.
\end{abstract}

Palavras-chave: psicanálise; laços sociais; parcerias amorosas; novas subjetividades; demanda de análise; castração.

Pair ou impair? Une vision à propos des nouvelles liaisons amoureuses entre hommes et femmes dans la clinique contemporaine.

Cette recherche fait face au désaccord qui éxiste entre le désir et le discours des hommes et des femmes de nos jours. Adoptant une perspective psychanalytique, nous évaluons les changements qui ont eu lieu dans la subjectiivité moderne et qui ont engendré l'échange du "lien par le mariage" contre un "éxil" dans lequel un nombre de personnes se trouvent actuellement. Il semble que la liberté sexuelle a étendu voire ralenti le choix d'un homme pour une femme et vice-versa. Car choisir implique en se faire castrer. Néanmoins, le sujet contemporain, traversé par l'idéologie qu'il est "interdit d'interdire", de pair avec une logique de capitalisme consommateur, semble croire que "tout est permis". Cette réflexion débouche, dans le cadre de la pratique psychanalytique, sur une demande du sujet contemporain et sur de nouvelles formes d'ecoute et de pratique clinique.

Mots-clés: psychoanalysis; lien sociaux; rapports amoureux; nouvelles subjectivités; demande d'analyse; castration.

\section{Evens or odds? A reading of the impasses deadlocks of new love partnerships between man and woman in contemporary clinical}

This research tackles the existing disagreement between desire and speech of men and women today. With a psychoanalytic perspective, we evaluate the changes that have occurred with subjectivities that have caused them to drift away from the bond of marriage, from modernity, towards an exile where many currently find themselves. It seems that sexual liberation has stretched and, it has sometimes delayed the choice of a man for a woman and vice-versa. Choice implies castration. However, the contemporary subject, caught in between the ideology that it is forbidden to forbid and the logic of consumerist capitalism, believes that it can "do it all". This reflection calls for the psychoanalytic method, aiming to address the demand of this contemporary subject and demanding a new type of clinical practice.

Key-words: psychoanalysis; social link; amorous partnerships; new subjectivities; analysis of demand; castration. 


\title{
Par ou Ímpar? Uma leitura dos impasses das parcerias amorosas entre homens e mulheres na clínica contemporânea
}

\author{
Márcia Infante Vieira
}

\section{Introdução}

Esse trabalho foi apresentado para banca de defesa de dissertação de mestrado do programa de pós-graduação em teoria psicanalítica da Universidade Federal do Estado do Rio de Janeiro, em março de 2016. O ponto de partida dessa pesquisa sãos os encontros e desencontros das parcerias amorosas, tal como podemos observá-los por meio da prática psicanalítica nos dias de hoje. No cenário social contemporâneo encontramos um número crescente de mulheres bem-sucedidas nas esferas profissional e econômica, livres para viverem sua vida sexual e que se queixam de solidão. Queixam-se de homens que fogem de um vínculo amoroso estável. Homens que as desejam por uma noite, ou que prolongam essa noite numa sequência de encontros que não são alinhavados pelo compromisso.

A minha percepção é de que, atualmente, apesar de homens e mulheres dizerem querer o encontro, o que se apresenta é uma aposta no desencontro. Identifico uma defasagem entre o discurso e a prática, ou seja, entre o que se diz e o que se busca. A comédia da vida amorosa da contemporaneidade difere dos enlaces do homem moderno. A modernidade era representada pelo casal obsessivo/histérica. Do lado do homem, o obsessivo, e sua incessante busca de satisfazer a mulher; e do lado da mulher, a histérica, com sua eterna insatisfação. A relação sexual não existia, mas esse casal cartografava um encontro, e se casava. Hoje, a solidão aparece como uma nova forma de viver. Ocorreram mudanças nos papeis sociais desempenhados tanto pelos homens, como pelas mulheres, que fizeram vacilar os semblantes do masculino e feminino.

A meu ver, essa mudança teve duas importantes alavancas. Primeiramente, a revolução sexual que trouxe a emancipação da mulher. Uma vez independentes economicamente, tornaram-se livres para escolher seus parceiros. Tendo a virgindade declinado de seu valor de passaporte para a vida marital, as mulheres se liberaram. Os homens diante desse novo cenário, viram-se frente a exigência de reconstruírem uma identidade ligada a um novo papel social. Não mais únicos provedores e, mais ainda, exigidos na performance sexual, até então inquestionada. $O$ mundo masculino ficou acrescido de uma psicodélica oferta de mulheres interessantes, que os colocou diante da dificuldade de escolher uma dentre tantas. Como segunda alavanca temos o avanço do capitalismo acumulativo, da modernidade, para um capitalismo de consumo, da contemporaneidade. O eixo do consumo parece perpassar as novas subjetividades e comprometer as escolhas amorosas. Vítimas e seduzidos pela política do desapego e do descartável, o sujeito contemporâneo busca o gozo, o imediato, o melhor produto. Eixo incompatível com a tolerância que a vida a dois exige. $O$ conflito entre o estar com ou sem alguém parece configurar as novas tonalidades do mal-estar do amor na contemporaneidade. Par ou ímpar? 


\section{Metodologia}

No primeiro capítulo tendo como base o livro da psicanalista Tânia Coelho dos Santos, Quem precisa de análise hoje? (2001), rastreei a história das parcerias amorosas entre os anos de 1950 a 1980. Nesse percurso destacaram-se três ideais: o ideal de harmonia, o ideal de autenticidade e o ideal do individualismo. Num segundo momento, analisei o cenário social vigente, articulando o narcisismo - herdeiro do ideal do individualismo - com o capitalismo. Essa articulação teve como pilar a leitura do historiador Christopher Lasch, a Cultura do Narcisismo: a vida americana numa era de esperanças em declínio (1983). A partir desse ponto, levantei algumas questões sobre o lugar do Outro na contemporaneidade, estudo novamente baseado no livro Quem precisa de análise hoje? (Coelho dos Santos, 2001). Em um terceiro tempo do primeiro capítulo, bordejei a questão sobre o que as mulheres buscam, atualmente, na análise, estudando as novas parcerias amorosas e suas novas demandas. Questionei se a saúde mental da mulher liberada seria a solidão? Fundamentei essa reflexão em três artigos de Coelho dos Santos: "Entre Tapas e Beijos: a vacilação dos semblantes da diferença sexual" (2008); "1968: A Vacilação Generalizada dos Papéis Sociais" (2008); e "Não existe pecado do lado de baixo do equador?" (2009).

No capítulo 2, inicialmente, me detive nos artigos da obra de Freud que se referem ao comportamento de homens e mulheres em relação ao amor e à sexualidade. Analisei os três artigos das Contribuições à Psicologia do Amor: I ("Um tipo de escolha de objeto feita pelos homens", 1910); II ("Sobre a tendência à depreciação na esfera do amor", 1912); e III ("O tabu da virgindade", 1917)". Esses artigos são frutos das impressões colhidas por Freud sobre a maneira como os neuróticos se comportam em relação ao amor. Freud não deixou de observar que esses mesmos comportamentos também podiam ser observados em pessoas de saúde normal. Incluí o artigo "Algumas Consequências Psíquicas da Distinção Anatômica entre os Sexos", (1925), por nele estar contida uma completa reavaliação de Freud ao que se refere ao desenvolvimento psicológico das mulheres. Seguindo a indicação do psicanalista Jacques-Alain Miller, feita em seus artigos, "Minha garota e eu" (1989) e "Uma conversa sobre o Amor" (1988), introduzi o texto "A significação do falo" (1958[1988]), de autoria do psicanalista Jacques Lacan, como a quarta contribuição à psicologia do amor. Por fim, utilizei as hipóteses de Miller, acerca desse mesmo tema.

No capítulo 3, evidenciei alguns marcos históricos que operaram mudanças na subjetividade e nos laços sociais. Ao destacar a existência de novos sintomas, denuncio ter ocorrido uma mudança na estruturação dos mesmos. Considero que da modernidade à contemporaneidade, a humanidade testemunhou o advento da ciência e a consequente morte de Deus, que se desdobrou no declínio da função paterna. Como consequência, a família nuclear deu lugar à família conjugal. A igualdade entre os sexos e entre as gerações passou a cartografar o cenário social, onde as bordas das diferenças sexuais e geracionais se fluidificaram. Surgiram novos sintomas. Como efeito, o sujeito neurótico, ou sujeito do conflito, deu lugar a um sujeito contemporâneo, angustiado, que vive no 
eixo do consumir-se ou ser consumido. Levei em conta que a psicanálise, através do exame dos casos individuais, estudou a cultura, sustentada pela crença de que toda sociedade, com suas normas e formas de organizar suas experiências, reproduz a cultura. Nessa via, Freud postulou que a mente inconsciente representa a imposição da civilização sobre as pulsões. A questão recortada tenta encontrar um caminho entre o sujeito moderno e o sujeito contemporâneo, seus laços sociais e seus sintomas. Utilizei o artigo de Jacques Lacan, "Complexos familiares na formação do indivíduo" (1938), para embasar nosso estudo sobre a modernidade. Dando prosseguimento às reflexões sobre os sintomas contemporâneos à luz do declínio da metáfora paterna, fiz uso do livro Sinthoma: corpo e Laço Social (2005), de Tânia Coelho dos Santos. Encerrei esse capítulo com algumas reflexões sobre os efeitos dessas mudanças nas cartografias das parcerias amorosas, onde o mal-estar que sempre existiu, parece ter sido tonalizado com as cores do impossível no cenário contemporâneo. Visando uma maior compreensão desses laços, elegi dois parâmetros: a intimidade e o movimento feminista. Para pensar a intimidade como um valor de moeda nessas parcerias, pautei minha pesquisa no livro do sociólogo Anthony Giddens (1993), A Transformação da Intimidade. Na sequência, trabalhei as ideias da filósofa Elisabeth Badinter (2005), extraídas do seu livro Rumo equivocado, onde a autora faz uma profunda análise sobre o movimento feminista e seus efeitos.

\section{Questões clínicas}

Como último ponto dessa dissertação, retornei para clínica, ponto de onde partiram as seguintes reflexões: Quais são os operadores que estão dando conta da prática psicanalítica? Como se escuta esse sujeito que se deslocou velozmente da modernidade para contemporaneidade? Sujeito que demanda ajuda em lidar com novas exigências, expectativas e negociações em sua vida conjugal. Do casal à um exílio em que muitos se encontram, o que teria ocorrido com as subjetividades dos homens e das mulheres?

\section{Vacilação dos papéis}

Na tentativa de responder essas questões, considerei, inicialmente, a pesquisa da psicanalista Tania Coelho dos Santos (2001), que analisa a entrada e consequente difusão da psicanálise no social, através das colunas de aconselhamento de revistas dirigidas ao público feminino. Essa entrada exerceu uma grande influência na desconstrução dos papéis desempenhados tanto pelos homens, como pelas mulheres no casamento, trazendo a reboque uma demanda de análise. A 'fala' das mulheres, ao longo dos anos, afetou a construção das parcerias amorosas. Uma vez emancipadas, passaram a questionar o autoritarismo do patriarcado. A sociedade patriarcal, que era organizada hierarquicamente no que se refere aos laços familiares, tornou-se mais democrática e igualitária. Num período de trinta anos, de 1950 a 1980, foi possível acompanhar o atravessamento de ideais que cartografavam esse cenário. Ocorreu um deslizamento do desempenho de papéis bem definidos no casal, que eram ancorados num ideal de harmonia, à uma exclusão do outro, como consequência 
do ideal do individualismo. Essa exclusão sendo efeito da busca de autenticidade, que passou a ser vislumbrada pela conquista do autoconhecimento. Banhado pelo ideal de autenticidade, o eu foi elevado à categoria de protagonista. Como resultante, um sujeito narcisista, que independente do sexo, passou a fugir do vínculo de compromisso, parecendo evitar o peso que a intimidade conferiu aos relacionamentos. De um lado o casal se aproximou. Nessa aproximação, observa-se que algo se descortinou como consequência do apagamento das bordas que definiam a diferença entre os sexos e as funções e papéis decorrentes. No entanto, o surgimento do mais íntimo de cada um, carregou a relação de uma potência emocional que desembocou, pelo excesso, num esgotamento do vínculo. A contrapartida desse excesso de aproximação teve como efeito o divórcio. A sociedade divorciou-se e os sexos entraram em guerra.

\section{Narcisismo e capitalismo}

Baseada nas ideias de Cristopher Lasch (1983) pude articular a subjetividade desse sujeito narcisista com a cultura do capitalismo. O sujeito desgarrado da história e dos laços sociais passou a visar o presente e o seu prazer, e por isso, encontra-se suspenso, rompido com o passado e com o Outro que o castra. Acredito que essa transformação contribuiu de forma a alimentar essa guerra entre os sexos. A experiência sexual, liberada das restrições anteriores, ganhou valor em si mesmo e ambos os sexos passaram a visar o mesmo, ou seja, ter prazer, mais e mais. Parece que homens e mulheres se destituíram do lugar de sujeito e ocuparam o lugar de objeto, uns para os outros. 0 que passa a ser buscado é o melhor produto, aquele que alcance o todo, ou seja, ter o melhor do feminino e o melhor do masculino simultaneamente. Na medida em que esse ideal é inalcançável, o outro, nesse momento esse outro que frustra por ser um objeto insatisfatório, é descartado. E a busca recomeça. Essa busca, apesar de preconizar a igualdade sexual, tem ao mesmo tempo, a marca da intolerância com a diferença. A leitura do narcisismo contemporâneo de Christopher Lasch (1983) aliada às ideias da psicanalista Coelho dos Santos (2001), demonstraram como a proposta individualista coloca o homem contemporâneo sem referências identificatórias. Na sociedade moderna ocidental, os sintomas neuróticos eram organizados a partir de um ideal coletivo por estarem referidos ao Nome-do-Pai. Atualmente, a ruptura com as tradições fez fraquejar o lugar do Outro, o que expôs o homem ao desbussolamento das pulsões. Sobrevivente do aqui e agora, ao mesmo tempo réu e vilão de seu destino, o homem psicológico encontra-se congelado no presente e descompromissado com o outro enquanto sujeito.

\section{Cenário atual}

Ao estudar a vacilação dos papéis que cabia a cada um na parceria amorosa, pude inferir que o sujeito moderno lidava com o machismo através de semblantes. Para o homem, o cavalheirismo, e para sua contrapartida feminina, a coqueteria. Os cavalheiros disfarçavam suas necessidades de dominação sobre o sexo feminino através do galanteio. As mulheres, como resposta, utilizavam-se 
da coqueteria para amansar a selvageria masculina, limitando o uso da força física por parte de seus parceiros. Não obstante, esse enredo não dissolveu a relação simbiótica entre explorador e explorado. As próprias mulheres alavancaram o declínio desse poder, na medida em que abriram mão de permanecerem confinadas num pedestal e desmistificaram a sexualidade feminina. Como consequência, esse tipo de relacionamento, baseado no sistema feudal, encontra o fim do caminho diante das revoluções democráticas dos séculos XVIII, XIX e XX. O cavalheirismo entrou em colapso.

Despidos desses semblantes, homens e mulheres viram-se diante da difícil tarefa de se reinventarem. Portadores, agora, de uma subjetividade narcísica, tinham como nova empreitada tornarem-se amigos e amantes, e tudo isso em posição de igualdade. Os papeis vacilaram e esse caminho parece sem volta. Apesar das mulheres terem perdido o status de dama através de um processo de desmistificação do feminino, dificilmente encontra-se, na atualidade, alguma mulher não identificada com os ganhos dessa liberação. A sexualidade feminina ganhou o espaço público desatrelando amor de prática sexual, que por sua vez, desvinculou-se do casamento e da procriação. O sexo passou a ser vivido como um valor em si mesmo, focado na vivência do prazer do momento, importando o presente, absolutamente desvinculado do futuro. Como efeito, perderam-se os referenciais que possibilitavam a permanência das relações. Pode-se inferir que um clima de boemia tomou conta da cena. Em outras palavras, o que antes era a prática dos boêmios, o descompromisso dos vínculos e o foco no prazer imediato, passa a ser o padrão do comportamento de ambos os sexos. Uma representação de uma mulher interessante, liberada, alegre, divertida e brincalhona ocupa o lugar da representação da mulher recatada, contida, e diante da qual a virgindade era cultuada.

As mulheres, da mesma maneira que os homens, desatrelaram na sexualidade, a via sensual da via amorosa, e passaram a exigir prazer sexual, diferente de suas antecessoras que viviam a vida sexual permeada por tensão e hesitação. Numa busca de equivalência com o sexo masculino topam assinar um contrato de relação sem compromisso, que mais cedo ou mais tarde as lançam numa devastação, oriunda de uma desvalia que se descortina. A tensão e a hesitação, nos dias de hoje, parecem localizarem-se na esfera do amor. A guerra dos sexos ganha cada vez mais adesões e as mulheres se furtam de assumir a diferença que as encarnam. Parece ser politicamente incorreto poder dizer: assim eu não quero. Essa exigência, ou equiparação feminina, tem como resposta masculina dois vetores. No primeiro vetor, as mulheres tornaram-se eleitas como parceiras sexuais, mas num segundo vetor, passaram a representar uma grande ameaça, já que se encontra embutida nessa demanda a necessidade de sua realização. Intimidados e com receio de não darem conta de tal feito os homens angustiaram-se. Logo, a proximidade trouxe riscos e vulnerabilidade emocional para os parceiros.

\section{Psicanálise e as condições para amar}

Revista aSEPHallus de Orientação Lacaniana. Rio de Janeiro, 11(21), 77-87, nov. 2015 a abr. 2016. 
Acredito ter havido uma banalização do sexo, que acaba por mascarar sua verdadeira raiz, ou seja, a força emocional proveniente das relações primevas com os pais. Essa hipótese acrescenta ao desencontro amoroso também motivações internas ao sujeito, onde a fuga ao compromisso relaciona-se ao caráter ameaçador que os impulsos internos podem encarnar. Por situar nesses impulsos e nas defesas erigidas contra eles a resposta à impossibilidade de um sexo satisfazer e completar o outro, me debrucei sobre a fonte do pensamento psicanalítico, ou seja, nas teorias freudianas sobre o amor, e na sequência, a de seus sucessores, a saber, Lacan e Miller. Meu objetivo é registrar que a heterossexualidade não tem como dar conta desses impulsos internos que se encontravam sob recalque na modernidade. Sendo assim, trabalhei com a hipótese de que a psicanálise tem como premissa ser o comportamento humano estruturado sobre a base de fantasias sexuais inconscientes. Essas fantasias, por sua vez, ancoram-se no enredo do Complexo de Édipo, que é vivido de forma diferente por cada sexo, ou seja, meninos e meninas diante da diferença sexual disparam respostas diferentes, que determinam o rumo de suas sexualidades, vindo a configurar seus comportamentos sexuais em suas vidas de adultos. A teoria sexual infantil da descoberta do pênis nos meninos e da ausência do mesmo nas meninas, não passa sem deixar marcas e exige elaboradas soluções. Essa experiência inaugura o que Freud conceitua como castração. Todo esse processo é inconsciente e suas soluções caem sob o recalque. Na vida adulta, a escolha do objeto amoroso é determinada pelo atravessamento desses impasses oriundos da castração. Diante das exposições dos artigos de Freud (1910; 1912;1917), de Lacan (1958) e de Miller (1988;1989), fica claro que essa escolha de um parceiro obedece determinadas condições, que visam, por sua vez, manter recalcado os impulsos mais primitivos de cada um envolvido na cena. Para Freud a sexualidade não tem como se desamarrar de obstáculos. O recalque tem como função integrar as pulsões sexuais parciais, e como efeito deixa um rastro. Esse rastro será a alavanca da construção das fantasias. Esse mecanismo representa a passagem do registro do gozo, das pulsões parciais, para o registro do desejo, que se instala após o mecanismo do recalque ter ocorrido e que visa a satisfação. Considero plausível pensar que diante do enfraquecimento do mecanismo do recalque o sujeito se veja diante das suas pulsões mais primitivas, pulsões essas, que visarão sempre o gozo.

Portanto, com o declínio do Nome-do-Pai, operador do recalque, pode-se concluir que o sujeito contemporâneo goza, não deseja. O que denuncia a ocorrência de um funcionamento mais na via do processo primário, do que no secundário, reforçando a hipótese de que esse sujeito age mais do que pensa. Não adia e recusa o que se interpõe na direção da sua rota de prazer. Outro ponto de relevância é que se o pai não tem mais a função de metáfora que interdita o gozo da mãe com o filho, o sujeito contemporâneo se vê diante desse mortífero eixo.

Se o sujeito moderno, sujeito freudiano, sujeito do recalque, na sua escolha amorosa vivia a divisão de duas representações da mulher, a da santa e a da puta, inferi que no momento em que essa divisão caiu, devido a liberação sexual das mulheres, os homens se angustiaram e passaram a 
fugir do compromisso. Essa angústia tendo como fonte o fato da mulher liberada ter passado a exigir do homem, a junção da corrente afetiva com a corrente sensual, tarefa difícil que os colocaram diante do fantasma da impotência, fruto da proibição do incesto. Do lado da mulher, fica como herança, a exigência de um trabalho de luto por não mais ocupar o lugar da dama na vida de um homem. Trabalho que as exige um giro sobre suas demandas de amor, pois por mais liberadas e apropriadas de seus corpos e de suas escolhas, ainda sofrem uma vez que não são eleitas para um vínculo permanente.

Esse desencaixe me remeteu a Lacan (1958) e a sua contribuição à psicologia do amor, onde conceituou o significante falo. Deslocou o tempo da castração, a um momento original, onde o infans é marcado pelo Outro na sua incompletude. Atribuiu ao falo a função de delimitar a diferença entre os sexos, e a diferença entre as gerações. Um sexo terá sempre como função apontar para o outro a incompletude, ou seja, a castração. Daí desdobra-se sua tese sobre a inexistência da relação sexual. A partir dessas reflexões fica evidente a inalcançabilidade do projeto individualista do sujeito narcísico contemporâneo. Marcado pelo Outro desde a origem, como o sujeito pode prescindir, na sua existência, dessa presença? Sem a abdicação da soberania da individualidade, o outro do amor não entra.

\section{Laço social: da lógica do todo à lógica do não-todo}

A constatação desse novo mal estar no enlace entre homens e mulheres me levou a pesquisar de que forma as mudanças na cultura, estruturante dos laços sociais, afetaram a estrutura psíquica do sujeito. A partir da articulação da lógica da sexuação preconizada por Lacan (2008) pensei as configurações dos laços sociais e suas transformações. Verifiquei que a lógica do todo, masculina, esta referida a uma sociedade patriarcal. Essa lógica que comandou o espetáculo da cartografia dos laços sociais na modernidade, parece não servir mais, pois a família patriarcal, com seus laços verticais, parece não fazer frente à uma lógica da igualdade de direito entre os sexos e entre as gerações. No entanto, a lógica que preconiza que é proibido proibir, lógica do não- todo, a lógica que não está submetida à castração, a lógica feminina, parece estar presidindo a formação dos encontros no contemporâneo. Pelo seu funcionamento, essa lógica estrutura encontros contingentes, e por isso, insatisfatórios e angustiantes. A lógica do todo significa que todo ser humano está submetido à castração, sendo essa, a verdadeira identificação. O deslizamento dessa lógica para a lógica do não- todo, ancorou os laços sociais, devido à ausência da diferença sexual como balizadora das subjetividades e sintomas, ao submetimento a um princípio do gozo como excesso. Esse excesso é oriundo da vacilação dos semblantes, pois os semblantes tinham como função regular a relação do sujeito com seu corpo, com seu gozo e com sua satisfação. Como efeito, um sujeito regulado pelo saber e pela sociedade de consumo. Sujeitos narcisistas comandados por um imperativo do gozo parece ser a subjetividade dominante no cenário social da contemporaneidade. Ao identificarem 
o mal-estar e o vazio dessa cena contemporânea em suas vidas, alguns chegam aos nossos consultórios demandando análise.

\section{De volta à clínica}

Respondendo à questão levantada na introdução: Quais são os operadores que estão dando conta da prática psicanalítica? Eu diria que os operadores continuam sendo os mesmos, se não perdemos de vista a castração. Isso quer dizer, um trabalho que propicie o sujeito se deslocar do campo do gozo para o campo do desejo. $\mathrm{O}$ analista precisa encontrar-se atento às transformações de sua época para que sua escuta esteja afinada com as mudanças subjetivas e com isso, identificar de que lugar o sujeito analisante está falando. Essa pesquisa me orientou no sentido de que esse sujeito está falando de um lugar onde acredita tudo poder. Um sujeito que desmente a castração, mas ao mesmo tempo tropeça nela. Tropeça pois não sustenta seu exílio, na medida que o Outro existe e a conta chega. Sua suspensão do tempo passado e futuro é furada pelas próprias frustações advindas da realidade objetiva. Viver o presente, acima de tudo, e o prazer máximo, acima de todos, parece ter prazo de validade. $O$ sofrimento de angústia é o sinal de que esse enredo fracassa. Cabe ao analista propiciar o diálogo com o real. O real da castração, ou seja, o real que aponta que não podemos tudo, que não nascemos todos livres e iguais, que nascer menino não é o mesmo que nascer menina, enfim ser homem não é igual a ser mulher.

Dessa forma, conclui a dissertação, acreditando que a prática psicanalítica continua não tendo como missão criar sujeitos adaptados ou engessados, mas, sim, permitir que através do atravessamento dos fantasmas singulares de cada sujeito, que inevitavelmente passa pelo reconhecimento da diferença sexual, cada um crie sua fórmula pessoal. Em outras palavras, esses sujeitos deslizam no sentido de atravessarem seus fantasmas quando orientados pelo real de seus sintomas. Castram-se e rearranjam suas vidas amorosas, sem que deixem de ser contemporâneos, já que em seus novos arranjos as mulheres não são destituídas de suas conquistas e nem os homens da tarefa de se reinventarem.

\section{Referências Bibliográficas}

Badinter, E. (2005). Rumo equivocado; o feminismo e alguns destinos. Rio de Janeiro: Civilização Brasileira.

Coelho dos Santos, T. (2001). Quem Precisa de Análise Hoje? O discurso analítico: novos sintomas e novos laços sociais. São Paulo: Bertrand Brasil.

Coelho dos Santos, T. (2006). Sinthoma: corpo e laço social. Transcrição do seminário ministrado por Tania Coelho dos Santos no PPGTP/IP/UFRJ no primeiro semestre de 2005. Rio de Janeiro: SEPHORA/UFRJ, 2006. 
Coelho dos Santos, T. (2008a). 1968: A Vacilação Generalizada dos Papéis Sociais. In Soubbotinik, O. M. S. \& Soubbotinik, M. (Orgs.). Enlaces, Psicanálise e Conexões, 1, 313-327. Vitória: Programa de Pós-graduação em letras e história da UFES.

Coelho dos Santos, T. (2008b). Entre Tapas e Beijos: a vacilação dos semblantes da diferença sexual. In Latusa - Revista da Escola Brasileira de Psicanálise, Seção Rio de Janeiro. Rio de Janeiro: EBP.

Coelho dos Santos, T. (2009). Não existe pecado do lado de baixo do equador? In Revista Cadernos de Psicanálise, 25(28), 121-142. Rio de Janeiro: SPCRJ.

Freud, S. (1976). Um tipo especial de escolha de objeto feita pelos homens (Contribuições à Psicologia do Amor I). In J. Salomão (Trad.). Edição Standard Brasileira das Obras Psicológicas Completas de Sigmund Freud (Vol. 11). Rio de Janeiro: Imago (Trabalho original publicado em 1910).

Freud, S. (1976). Sobre a tendência à depreciação na esfera do amor (Contribuições à Psicologia do Amor II). In J. Salomão (Trad.). Edição Standard Brasileira das Obras Psicológicas Completas de Sigmund Freud (Vol. 11). Rio de Janeiro: Imago (Trabalho original publicado em 1912).

Freud, S. (1976). O Tabu da Virgindade (Contribuições à Psicologia do Amor III). In J. Salomão (Trad.). Edição Standard Brasileira das Obras Psicológicas Completas de Sigmund Freud (Vol. 11). Rio de Janeiro: Imago (Trabalho original publicado em 1917).

Freud, S. (1976). Consequências psíquicas da distinção anatômica entre os sexos. In J. Salomão (Trad.). Edição Standard Brasileira das Obras Psicológicas Completas de Sigmund Freud (Vol. 19). Rio de Janeiro: Imago (Trabalho original publicado em 1925).

Giddens, A. (1993). A Transformação da Intimidade; sexualidade, amor e erotismo nas sociedades modernas. São Paulo: Editora da Universidade Estadual Paulista.

Lacan, J. (1997). O seminário, livro 7: a ética da psicanálise. Rio de Janeiro: Zahar (Trabalho original publicado em 1959-1960).

Lacan, J. (1998). A significação do falo. In Escritos, pp. 692-703. Rio de Janeiro: Zahar (Trabalho original publicado em 1958).

Lacan, J. (1998). A ciência e a verdade. Escritos. Rio de Janeiro: Zahar (Trabalho original publicado em 1965-1966).

Lacan, J. (2003). Complexos Familiares na formação do indivíduo. In Outros Escritos. Rio de Janeiro: Zahar (Trabalho original publicado em 1938).

Lacan, J. (1992). O Seminário, livro 17: o avesso da psicanálise. Rio de Janeiro: Zahar (Trabalho original publicado em 1969-1970).

Lacan, J. (1985). O Seminário, livro 20: mais, ainda. Rio de Janeiro: Zahar (Trabalho original publicado em 1972-1973). 
Lasch, C. (1983). A Cultura do Narcisismo - a vida americana numa era de esperanças em declínio. Rio de Janeiro: Imago.

Miller, J.-A. (2010, jul.). Uma conversa sobre o amor. In Opção Lacaniana online nova série, 1(2).

Miller, J.-A. (2003, ago.). Uma partilha sexual. In Clique (2). Revista dos Institutos Brasileiros de Psicanálise do Campo Freudiano MG: Instituto de Saúde Mental de Minas Gerais, agosto, 2003. Miller, J.-A. (2004-2005). Pièces detachés - Seminário de Orientação Lacaniana.

Citacão/Citation: Vieira, M. I. (nov. 2015 a abr. 2016). Par ou Ímpar? Uma leitura dos impasses das parcerias amorosas entre homens e mulheres na clínica contemporânea. Revista aSEPHallus de Orientação Lacaniana, 11(21), 77-87. Disponível em www. isepol.com/asephallus. doi: 10.17852/1809-709x.2019v11n21p77-87.

Editor do artigo: Tania Coelho dos Santos.

Recebido/Received: 24/03/2016 / 03/24/2016.

Aceito/Accepted: 18/04/2016 / 04/18/2016.

Copyright: (C) 2013 Associação Núcleo Sephora de Pesquisa sobre o moderno e o contemporâneo. Este é um artigo de livre acesso, que permite uso irrestrito, distribuição e reprodução em qualquer meio, desde que o autor e a fonte sejam citados/This is an open-access article, which permites unrestricted use, distribution, and reproduction in any medium, provided the author and source are credited. 